\title{
EDITORIAL
}

\section{Defining chronic obstructive pulmonary disease... and the elephant in the room}

\author{
D.M. Mannino
}

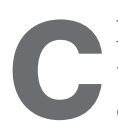

hronic obstructive pulmonary disease (COPD) is one of the leading causes of disability and death in both the developed and developing world [1]. We are starting to understand about pathogenesis, progression and prognosis in COPD, but the understanding of any disease starts with defining what one is actually talking about [2].

So what constitutes disease in COPD? Combinations of the forced expiratory volume in one second (FEV1), forced vital capacity (FVC) and the slow vital capacity (SVC) are used to help classify lung disease. What is normal? What reference equations does one use? Is the lower limit of normal (LLN) for the FEV1/FVC more accurate than the fixed ratio of 0.70 ? Does lung function have to be measured after bronchodilation? All of the factors mentioned contribute to the determination of COPD prevalence in populations, as is seen in the article by SHIRTCLIFFE et al. [3] in the current issue of the European Respiratory Journal.

What is "normal"? An online dictionary lists the following definitions: "Conforming with, adhering to, or constituting a norm, standard, pattern, level, or type; typical. Functioning or occurring in a natural way; lacking observable abnormalities or deficiencies. Occurring naturally and not because of disease, inoculation, or any experimental treatment" [4]. A related question is: what constitutes "disease"? In discussing COPD, SNIDER [2] defined disease as: "a condition or state in a group of persons who have specified characteristics by which they differ from the norm in a way that is biologically disadvantageous." One can get into philosophical discussions over what actually constitutes disease in contrast to normal variation, affects of ageing or artefacts of how medical information is captured. While there is no clear-cut answer to what constitutes disease, it could be argued that a finding that predicts a bad event or premature death probably represents disease. For example, there is nothing intrinsically problematic with a person walking around with a diastolic blood pressure of $100 \mathrm{mmHg}$. This person may well look like and function as well as a person with a diastolic pressure of $80 \mathrm{mmHg}$. The problem with the first person relates to their prognosis and risk of stroke and premature mortality [5].

STATEMENT OF INTEREST: None declared.

CORRESPONDENCE: D.M. Mannino, Dept of Preventive Medicine and Environmental Health, University of Kentucky College of Public Health, 121 Washington Avenue, Lexington, KY 40536 , USA. Fax: 18592572418. E-mail: dmannino@uky.edu
In the article by SHIRTCLIFFE et al. [3], local reference equations are used. There is certainly a rationale for this in that equipment, procedures and anthropomorphic characteristics of the population may vary from one area to another. However, a risk of local prediction equations is that if a large part of the population has exposures or abnormality then the ability to find this abnormality is lost. If a population was used in which everyone was a smoker, prediction equations from this population would be less likely to find an effect of smoking on lung function. While this seems an unlikely scenario, it is entirely possible that prediction equations from parts of the developing world where virtually the entire population is exposed to biomass smoke might miss this effect by focusing on the local "norms".

Is the LLN for the FEV1/FVC more accurate than the fixed ratio of 0.70 ? Global initiative for chronic Obstructive Lung Disease (GOLD) criteria recommend the fixed ratio [6], whereas the American Thoracic Society/European Respiratory Society guidelines recommend the LLN [7]. The rationale for the GOLD schema is based on the desire for simplicity, since perception of the complexity of spirometry and its interpretation has been one of the barriers to more widespread uptake of this simple clinical tool. The perceived risk of using the fixed ratio is "overdiagnosing" disease in the elderly and "underdiagnosing" disease in younger adults $[8,9]$. A recent longitudinal study of an elderly cohort showed that subjects classified as normal using the LLN but abnormal using the fixed ratio were more likely to die and to have a COPD-related hospitalisation during follow-up [10].

How important is the use of post-bronchodilator lung function? The GOLD guidelines recommend this, and some have argued that the "ceiling" of lung function (i.e. the best possible lung function that a person might have) is what is important in classifying disease [11]. Post-bronchodilator can lower the estimate of COPD prevalence by $30-50 \%[12,13]$. In contrast, studies that have looked at the relationship between COPD and adverse outcomes, such as lung cancer and death, have frequently used pre-bronchodilator lung function, since, in most longitudinal databases, post-bronchodilator lung function is not available [14-16]. Is post-bronchodilator lung function a better predictor of mortality in COPD? This is an open question. In one asthma cohort the "best FVC" predicted mortality [17], whereas in another asthma cohort subjects with $>50 \%$ reversibility in FEV1 had the highest mortality [18].

In the study by SHIRTCLIFFE et al. [3], the agreement between the different strategies of classifying COPD (i.e. the GOLD criteria 
(fixed ratio of 0.70 for FEV1/FVC), pre-bronchodilator LLN for the FEV1/FVC, post-bronchodilator LLN for FEV1/FVC, and post-bronchodilator LLN for FEV1/SVC) was actually pretty good, with kappa values ranging 0.66-0.89 (table 4 in [3]). These different stratification schemes resulted in variation in age-adjusted COPD prevalence (among people aged $\geqslant 40 \mathrm{yrs}$ ) of $9.0-15.2 \%$ (table 3 in [3]).

So what is the elephant in the room? In the analysis conducted by SHIRTCLIFFE et al. [3], "diagnosed" COPD had almost no relation to any measure of spirometrically determined COPD, with kappa values ranging from a dismal 0.06 to 0.09 . For reference, a kappa value of 0 would translate to absolutely no relation between "diagnosed" COPD and that measured with spirometry. This is not a unique finding. COPD, defined using spirometric measures, has been consistently underdiagnosed in sites in which this has been evaluated, sites as diverse as the USA [19], England [20], Central and South America [21], Korea [22] and now New Zealand [3].

Splitting hairs over the most precise definition of COPD while many people with disease are undiagnosed and untreated, because primary care providers are confused by the multiplicity of these definitions, is a disservice to patients and the medical community. I cast my vote for simplicity and support both the fixed ratio of 0.70 and pre-bronchodilator lung function to classify most individuals. This is a concept that is easy to understand and can be quickly explained to medical students, physician assistants and other care providers. I also support the idea that any type of intervention (other than the cessation of smoking) must be based on factors other than GOLD criteria or other criteria classifying lung function impairment. Specifically, an elderly person with mild impairment according to GOLD criteria but no symptoms will not receive additional treatment in my clinic.

The best way to improve the detection of chronic obstructive pulmonary disease in the populations we treat is to increase the use of spirometry in primary care settings. Doing this in a way that yields reliable results has proven challenging, but improvements in technology are helping to achieve this goal. Simple and reasonably accurate classification schemes that primary care providers can understand and apply will, ultimately, result in improved detection of disease and outcomes for our patients.

\section{REFERENCES}

1 Lopez AD, Mathers CD, Ezzati M, Jamison DT, Murray CJL. Global Burden of Disease and Risk Factors. Washington, The World Bank, 2006.

2 Snider GL. Nosology for our day: its application to chronic obstructive pulmonary disease. Am J Respir Crit Care Med 2003; 167: 678-683.

3 Shirtcliffe P, Weatherall M, Marsh S, et al. COPD prevalence in a random population survey: a matter of definition. Eur Respir J 2007; 30: 232-239.

4 Answers.com. Normal. www.answers.com/normal\&r=67. Date last accessed: April 2007.

5 Psaty BM, Furberg CD, Kuller LH, et al. Association between blood pressure level and the risk of myocardial infarction, stroke, and total mortality: the cardiovascular health study. Arch Intern Med 2001; 161: 1183-1192.
6 Global Initiative for Chronic Obstructive Lung Disease (GOLD) 2006. Global Strategy for Diagnosis, Management, and Prevention of COPD. www.goldcopd.com/ Guidelineitem.asp? $11=2 \& 12=1 \&$ intId $=989$. Date last accessed: April 2007. Date last updated: November 2006.

7 Pellegrino R, Viegi G, Brusasco V, et al. Interpretative strategies for lung function tests. Eur Respir J 2005; 26: 948-968.

8 Hnizdo E, Glindmeyer HW, Petsonk EL, Enright P, Buist AS. Case definitions for chronic obstructive pulmonary disease. COPD 2006; 3: 95-100.

9 Hardie JA, Buist AS, Vollmer WM, Ellingsen I, Bakke PS, Morkve O. Risk of over-diagnosis of COPD in asymptomatic elderly never-smokers. Eur Respir J 2002; 20: 1117-1122.

10 Mannino DM, Sonia Buist A, Vollmer WM. Chronic obstructive pulmonary disease in the older adult: what defines abnormal lung function? Thorax 2007; 62: 237-241.

11 Sterk PJ. Let's not forget: the GOLD criteria for COPD are based on post-bronchodilator FEV1. Eur Respir J 2004; 23: 497-498.

12 Johannessen A, Omenaas ER, Bakke PS, Gulsvik A. Implications of reversibility testing on prevalence and risk factors for chronic obstructive pulmonary disease: a community study. Thorax 2005; 60: 842-847.

13 Kim SJ, Suk MH, Choi HM, et al. The local prevalence of COPD by post-bronchodilator GOLD criteria in Korea. Int J Tuberc Lung Dis 2006; 10: 1393-1398.

14 Mannino DM, Doherty DE, Sonia Buist A. Global Initiative on Obstructive Lung Disease (GOLD) classification of lung disease and mortality: findings from the Atherosclerosis Risk in Communities (ARIC) study. Respir Med 2006; 100: 115-122.

15 Stavem K, Aaser E, Sandvik L, et al. Lung function, smoking and mortality in a 26-year follow-up of healthy middle-aged males. Eur Respir J 2005; 25: 618-625.

16 Purdue MP, Gold L, Jarvholm B, Alavanja MC, Ward MH, Vermeulen R. Impaired lung function and lung cancer incidence in a cohort of Swedish construction workers. Thorax 2007; 62: 51-56.

17 Connolly CK, Mamun M, Alcock SM, Prescott RJ. The Darlington and Northallerton Prospective Asthma Study: best function predicts mortality during the first 10 years. Respir Med 1998; 92: 1274-1280.

18 Ulrik CS, Frederiksen J. Mortality and markers of risk of asthma death among 1,075 outpatients with asthma. Chest 1995; 108: 10-15.

19 Mannino DM, Gagnon RC, Petty TL, Lydick E. Obstructive lung disease and low lung function in adults in the United States: data from the National Health and Nutrition Examination Survey, 1988-1994. Arch Intern Med 2000; 160: 1683-1689.

20 Shahab L, Jarvis MJ, Britton J, West R. Chronic obstructive pulmonary disease prevalence, diagnosis and relation to tobacco dependance in a nationally representative population sample. Thorax 2006; 61: 1043-1047.

21 Talamo C, de Oca MM, Halbert R, et al. Diagnostic labeling of COPD in five Latin American cities. Chest 2007; 131: 60-67.

22 Kim DS, Kim YS, Jung KS, et al. Prevalence of chronic obstructive pulmonary disease in Korea: a population-based spirometry survey. Am J Respir Crit Care Med 2005; 172: 842-847. 